\title{
EPISTEMOLOGIA-ONTOLOGIA-METODOLOGIA PELA DIFERENÇA: LOCUS TRANSFRONTEIRA EM IRONIA MULTIMODAL
}

\author{
EPISTEMOLOGY-ONTOLOGY-METHODOLOGY OF \\ DIFFERENCE: TRANSBOUNDARY LOCUS IN MULTIMODAL \\ IRONY
}

\section{Nara Hiroko Takaki*}

\section{RESUMO}

Este artigo pretende contribuir para uma reflexão sobre a maneira de compreender multimodalidade, com destaque para o lócus fronteiriço em que a construção de sentido ocorre. Dessa forma, apresentamos e discutimos como estudantes de Curso de Letras, cada vez mais imersos nos meios tecnológicos, compreendem parte dos cenários político e educacional atual no Brasil e como se apropriam da canção Que país é esse? e do vídeo clip de Another brick in the wall para então produzir um vídeo com recursos disponíveis, cujo fio condutor é uma ironia. A avaliação de Another brick in the wall pelos alunos e a visão da pesquisadora, autora deste artigo, instigam relações de crise que circulam nos âmbitos políticos, sociais e educacionais do Brasil. Para a produção do vídeo a noção de pensamento de fronteira (MIGNOLO, 2008) é contemplada. Ela requer ser ouvida pela diferença e está interligada à metodologia adotada, ou seja, de natureza qualitativa, interpretativa e descritiva. Sugere-se, assim, uma ampliação no conceito de multimodalidade (KRESS, 2003, 2010), ou seja, uma multimodalidade de transfronteira que chama a atenção para processos ambíguos e multidirecionais de articulação de sentidos e saberes. Conclui-se que a criatividade, aprendizagem e transformação são possíveis quando há abertura para maiores discussões envolvendo o papel da língua/linguagem, o uso de tecnologias e a perspectiva de formação de cidadãos (FREIRE, 2005) pelas Letras.

Palavras-chave: multimodalidade de transfronteira; conhecimento criativo; aprendizagem transformativa

\section{ABSTRACT}

This article aims at contributing to a reflection upon ways to understand multimodality, highlighting the border locus in which meaning making occurs. In this way, we present and discuss how undergraduate students of a language course immersed in technological environments understand parts of the political and educational landscapes in Brazil and how they appropriate the song "Que país é esse?" and the video clip of Another brick in the wall to produce another video with available resources, whose central thread is an irony. The evaluation of another brick in the wall by the students and by the researcher, who is also

\footnotetext{
*Universidade Federal do Mato grosso do Sul, Campo Grande, MS (Brasil).narahi08@gmail.com
} http://dx.doi.org/10.1590/010318134907175031 
the author of this paper, recognizes the crisis in relationships between political, social and educational realms in Brazil. For the video production, the notion of border thinking (MIGNOLO, 2008) is used. It demands difference be recognized and it is interlinked to the methodology adopted, that is, of a qualitative, interpretive and descriptive nature. Thus, a broader concept of multimodality (KRESS, 2003, 2010) is suggested, that is a transboundary multimodality which calls attention to the ambiguous and multidirectional processes of articulation of meanings and knowledge. The article concludes that creativity, learning and transformation are possible when there is openness to transcultural discussions involving the role of language, the use of technology and the perspective of citizenship (FREIRE, 2005) through language resources.

Keywords: transboundary multimodality; creative knowledge; transformative learning.

\section{INTRODUÇÃO}

Observa-se que nos currículos, em geral, há uma programação de conteúdos que pode dar a entender, para muitos professores, que o conhecimento é construído apenas linearmente, que pressupõe a aprendizagem de um item antes do outro e assim sucessivamente. Na escolaridade convencional, há uma linearidade de estruturas e conteúdo para serem ensinados. Dizeres como: se não aprenderam $X$, então não conseguirão fazer $Y$, pode servir em certas situações, mas não necessariamente em todas. Consequentemente, muitos docentes podem ter dificuldade de descobrir maneiras para incluir outras escutas, sentidos e saberes das conversas diárias dos estudantes nas práticas de letramentos da sala de aula. Possivelmente os estudantes agradeceriam se essas outras práticas de letramentos fizessem parte de seus currículos escolares com discussões sobre as implicações delas nas relações sociais. É justamente nesse ponto que o objeto de investigação deste artigo procura enfatizar o reconhecimento e a inclusão das práticas e estratégias de negociação de significação nas interações diárias que envolvem, por exemplo, jogos, produção de vídeos domésticos, desenhos, memes, piadas e informalidades comunicativas em ambientes urbanos e rurais etc. Esses exemplos de letramentos favorecem à revitalização dos relacionamentos entre as pessoas de diferentes idades, origens, culturas, conhecimento de mundo e as instituições de ensino representam espaços propícios para valorizar tais práticas sociais.

Uma forma de olhar para essas sugestões de letramentos pluralizados é a pesquisa em contexto universitário. A proposta deste artigo está imersa nessa linha de raciocínio e é parte de uma pesquisa intitulada Novos letramentos e multiletramentos no ensino de letras em línguas: ressignificando em tempos globais de um Curso de Letras de uma universidade pública. Ela poderá contribuir no sentido de que o trabalho com letramentos em sociedade digital requer do pesquisador e de seus participantes de pesquisa pensar e agir para além do senso comum. Essa prática que cultiva 
transculturalidades e transdisciplinaridades ocorre não necessariamente por meio de comunicação verbal convencional, mas também por multimodalidade ${ }^{1}$ (KRESS, 2003, 2010) e raciocínios/pensamentos paralelos que desafiam os historicamente legitimados. Assim, o teor dessa perspectiva assume as heterogeneidades/diferenças como processos incompletos e sujeitos às mudanças contextuais históricas e isso vem ganhando adeptos por parte de teóricos e leitores da Linguística Aplicada atual.

Abro a discussão apresentando a inseparabilidade entre epistemologia, ontologia e metodologia, que serve tanto para o ensino quanto para a pesquisa. Prossigo argumentando que as multimodalidades não podem faltar nos trabalhos de letramentos locais-globais. A seguir, contextualizo uma situação de produção de vídeo pelos estudantes de Letras na universidade onde atuo, analisando e discutindo como eles compreendem e modificam duas produções musicais. Por fim, aceno para as implicações das perspectivas teóricas adotadas por eles e por mim quanto à formação cidadã no âmbito da Linguística Aplicada atual.

\section{OUVINDO EPISTEMOLOGIA-ONTOLOGIA-METODOLOGIA PELA DIFERENÇA}

Da relação entre língua/linguagem e seus usuários, poderá haver perturbações ligadas às questões de pertencimento sociocultural, tensão, parceria, resolução, continuidade, raciocínios outros para a criação de ideias e projetos, por exemplo. Mas o exercício da criatividade poderá não ser suficiente para o acesso a tais objetos/ elementos. É que a criatividade necessita de um aliado que é a criticidade, o que ajuda a incorporar as vozes das pessoas que não têm tido acesso a bens culturais ou a espaços públicos em que a participação política delas pudesse lhes render benefícios sociais. Essas vozes compreendem aquelas dos grupos que se encontram em situações de alta vulnerabilidade social no globo (crianças, mulheres, negros, quilombolas, indígenas, refugiados, alguns estudantes e escolas públicas, animais, dentre outros). Muitas vezes esses grupos são estereotipados por conta de visões eurocêntricas propagadas pela mídia.

Esses raciocínios, traduzidos como pensar de outra maneira que não a do senso comum, possibilitam instaurar um conjunto de diálogos, debates e práticas que visam a justamente desmontar práticas e discursos pré-estabelecidos como verdadeiros na sociedade. Num âmbito educacional, semelhantes práticas reconhecem, por exemplo, que as histórias locais (em que as ideias e os projetos

\footnotetext{
${ }^{1}$ Ouso usar a palavra multimodalidade na forma plural em função das complexidades dinâmicas já existentes muito antes da emergência das novas mídias.
} 
intelectuais são produzidos na interseção de línguas/linguagens silenciadas e nas línguas/linguagens que silenciam) não gozam da mesma atenção que as histórias eurocêntricas recebem.

Contudo, as dicotomias entre conceitos não se sustentam, por si só, por haver interconexões entre bistórias locais e projetos globais (MIGNOLO, 2000, p. 71) por conta de que o pensamento fronteiriço não possui local pré-definido. É justamente pelo fato de não podermos vivenciar as situações conjunta e simultaneamente que insistimos em não nos distanciar delas e de outras afins. O que isso mostra? Mostra que somos movidos pela diferença colonial (MIGNOLO, 2000) ou aquilo que poderá vir a ser diferente (DERRIDA, 1994), ou seja, inusitado, ambíguo, híbrido, contingente.

O que chama a atenção em tal pensamento orienta-se pela decolonização epistêmica ${ }^{2}$ que não ignora os conceitos eurocêntricos, antes reconhece de onde os pensamentos foram negados pelo pensamento da modernidade (exs: ideologias do cristianismo, liberalismo, marxismo, conservadorismo e colonialismo), pelos pensamentos de esquerda ou direita e os problematiza de maneira a "aprender a desaprender (MIGNOLO, 2008, p. 290-291), reconhecendo que a América Latina marca diferentes configurações coloniais, não sendo, portanto, extensões da Europa". O preço é desaprender os valores advindos de países ocidentais que se espalharam pelo mundo via processos de colonização na América Latina e que responde pela exaltação de raças, culturas, etnias e conhecimentos do branco europeu. Para que haja fomento à produção de saberes pós-ocidentalistas ${ }^{3}$, uma epistemologia fronteiriça é desejável. A epistemologia influencia tanto a ontologia como a metodologia, como dito anteriormente. Logo, pode-se deduzir que esse tripé vivo respira pelas veias fronteiriças.

O que caracteriza o "pensamento de fronteira" são as experiências de dentro da América Latina que são teorizadas por intelectuais daqui e a perspectiva do subalterno ativo e não as experiências exportadas para os intelectuais do norte teorizarem e aplicarem. O subalterno é um suposto subalterno se este se propõe a questionar, resistir e transformar o pensar e agir ocidentais, ou seja, "se engajar na criação de teorias fora dos limites dos binarismos e dicotomias fixas em prismas

\footnotetext{
${ }^{2}$ Por decolonização epistêmica entendemos ser um processo contínuo de produção de conhecimento, de outros discursos, recursos, visões, saberes deslocando as práticas do centro do europeu sem desconsiderá-los.

${ }^{3} \mathrm{O}$ citado autor prefere usar o adjetivo pós-ocidentais ao invés de pós-coloniais por aquele ser da América Latina e o último ter emergido em países de língua inglesa, o que requer um imaginário teórico diferente.
} 
globais" (MIGNOLO, 2008, p. 146), tais como: centro e margem; colonizador, colonizado; civilizado, primitivo/bárbaro etc.

Essa tarefa pode ser viabilizada quando a produção de saberes for originada num lócus que instaure o cruzamento das experiências históricas e interpretativas começando nas escolas e nas universidades. Isso por conta de que a maioria das universidades, em países que são ex-colônias, produz conhecimento com base nas estruturas e epistemologias-ontologias-metodologias, enfim, teorias-práticas importadas com maior ou menor grau de adaptação local, mas com certo idealismo inspirado nas fontes eurocêntricas, apostando que os valores de tais fontes dão conta das heterogeneidades e complexidades transculturais emergentes.

Uma articulação geopolítica e geo-histórica da ordem mundial do momento pede uma epistemologia de fronteira que não deixe que a noção de América Latina se uniformize no horizonte nas histórias locais das configurações globais mutantes. É questionar uma vez mais todas as formas coloniais/nacionais de identificação no sistema mundial moderno/colonial (MIGNOLO, 2008, p. 171).

Nesses termos, a epistemologia (modos de pensar para produzir sentidos e saberes) depende da ontologia (modos de ser sendo), mas de uma ontologia que aceita a diferença/diversidade, isto é, o outro. Esse outro não seria o inferior, o subalterno e sim o complementar daquilo que é visto como sendo o mesmo/ semelhante/igual e esse se situa na perspectiva das histórias locais sem essencializálas. Esboça-se, assim, um tipo de cidadania em que o questionamento (das narrativas hegemônicas) e o autoquestionamento (de tais histórias locais), numa via de mão dupla, podem suscitar outros deslocamentos de sentidos e conhecimentos de outrora. Vejamos, pois:

\begin{abstract}
A alternativa é uma dupla crítica, aos viajantes e aos proprietários: aos viajantes e proprietários em posições hegemônicas da perspectiva dos viajantes e proprietários em posições subalternas. Isso são, basicamente, as condições históricas do pensamento fronteiriço ou epistemologias de fronteiras, emergindo de uma perspectiva crítica sobre a colonialidade de poder ou diferença colonial (MIGNOLO, 2008, p. 174).
\end{abstract}

A diferença colonial ou colonialidade de poder ${ }^{4}$ (QUIJANO, 2005, p. 207) pressupõe a compreensão das regras "contratuais" e das formas de dominação de estilo modernista com alcance que distingue a história colonial da Índia (sob o domínio do império britânico) da história colonial das Américas (Latina, AngloAmericana e Caribenha) com as consequências dos domínios eurocêntricos. Tais

\footnotetext{
${ }^{4}$ É um modelo de poder que afirma a superioridade étnica do branco europeu e controla o trabalho e a produção de conhecimento.
} 
domínios reprimiram indígenas americanos, africanos e caribenhos, dentre outros, e abriram espaço para sucessivos legados coloniais e imperiais envolvendo tensões regionais, nacionais e transnacionais nos quais as relações de poder sempre se construíram trans-simetricamente.

Sob essa ótica, a produção de sentidos e de saberes viveu sempre sob o signo da mobilidade, porém sempre ancorada num contexto:

Se de fato as teorias viajam e se tornam transculturais, é preciso antes especificar, historicamente, de onde elas partem, e para onde vão, como elas viajam, como elas se tornam transculturais, e a língua na qual as teorias viajantes são produzidas, empacotadas, e se tranculturam. A colonialidade de poder e a diferença colonial são os "inconvenientes" inevitáveis da viagem (MIGNOLO, 2008, p.184).

Em que pese o fato das teorias e dos teóricos viajarem, suas locações geohistórias e geopolíticas os acompanham. Isso não significa dizer que tanto as teorias como os teóricos se alojam em novos loci necessariamente replicando suas práticas sociais com seus corpos e mentes marcadas por experiências características da colonialidade de poder (QUIJANO, 2005, p. 207).

A colonialidade depoder, segundo o referido teórico, é um princípio e estratégia de controle que não negam os efeitos positivos da modernidade em suas manifestações europeias, mas consideram seus efeitos escurecidos no planeta e protestam por mais pensamentos no sistema moderno/colonial. As etnias e raças não europeias seriam alvos do cristianismo, de missões civilizatórias, do capitalismo, desenvolvimento e consumo e da modernização. Esse autor entende que a modernidade é uma das histórias locais e fluidas como as outras. Entretanto, ela acabou obliterando referências às intersubjetividades fora de contextos europeus. Ele enfatiza que para seguir adiante é desejável que se descolonize o conhecimento problematizando as diferenças coloniais partindo da heterogeneidade como sendo ramificada, ou seja, uma dimensão global mais interconectada que viria a expandir a compreensão das complexidades nas Américas.

Nessa lógica, "o pensamento não viaja, mas opera na intersecção de memórias e informações, de decisões passadas, de eventos atuais e nas possibilidades utópicas" (MIGNOLO, 2008, p. 186). Talvez mais importante que dizer que algumas teorias e teóricos viajam mais que outros (o citado autor pontua que as teorias em língua inglesa viajam de primeira classe e chegam mais rapidamente aos seus destinos) é indagar sobre o porquê de uma teoria ser mais desejável para um determinado contexto que outras e seus impactos, ou seja, como isso significa para as pessoas e culturas que ali se articulam. 
A agência humana existe pelo simples fato de que as pessoas percebem, adaptam, mudam seus sentidos e atividades quando em contato com a temporalidade que floresce das suas relações sociais. A compreensão do trabalho das línguas/ linguagens se tornou uma exigência na sociedade de aprendizagens, o que favorece outras alterações e reflexões devido ao fato dela ser interpelada pelas novas mídias. Pautamo-nos na visão de que a língua/linguagem não é uma substância, uma essência que acumula e se universaliza na história. Ao contrário, a língua/linguagem é um sistema de significados em forma de performatividade (PENNYCOOK, 2010), que são processos em arenas de negociações situadas. Tais processos não vêm de origens definidas nem convergem para destinos certos. No cenário da globalização e das tecnologias de informação e comunicação, a sociedade se encontra em mudanças impactantes, aceleradas e irreversíveis nas ações das pessoas.

O caráter performativo abre-se para relações significativas entre língua/ linguagem e identidade com forças produtivas que marcam diferenças culturais. É por meio de performatividade pluralizada que os discursos e os sujeitos deles são construídos permanentemente. A cada emergência, um contexto se configura para novas interações, de modo que o:

lócus de enunciação e a locação das teorias revelam constantemente que a base das teorias não é um sujeito universal situado na história local do Ocidente, mas uma produção teórica e a auto definição de teorias em línguas específicas e histórias locais. São as histórias locais que clamam por pensamento (MIGNOLO, 2008, p. 190).

Em decorrência, os sistemas de conhecimentos monoculturais não consideraram as diferenças da América Latina do ponto de vista da colonização, o que lança o Brasil e outros países, por exemplo, para as margens/periferias do centro. Isso porque os discursos centrados na modernidade, pós-modernidade e civilização ocidentais deixaram de fora a dimensão planetária da história humana. Propositadamente, português e espanhol são línguas e languaging ${ }^{5}$ subalternas das culturas subalternas que têm sido foco de reinvenção do campo de pesquisa, ou seja, das reconstituições coloniais da modernidade e da pós-modernidade.

Por outro lado, se as periferias são mutáveis, então nem todos os lugares estão ancorados em periferias cristalizadas e pensar a partir desse locus significa pensar projetos globais transculturando-os em projetos locais relevantes para as culturas periféricas, rearticulando saberes e discursos da visão crítica subalterna. É o que Nolasco $(2013$, p. 86) entende como alternativa.

\footnotetext{
${ }^{5}$ Languaging significa pensar e escrever entre línguas/linguagens como uma prática cultural e luta pelo poder (MIGNOLO, 2008, p. 226-227). Amplio esse conceito para a produção de sentidos e saberes multiplarmente não somente por meio da escrita em si.
} 
$\mathrm{O}$ que uma epistemologia-ontologia-metodologia fronteiriça teria a ver com as multimodalidades presentes nas comunidades orais (SOUZA, 2004) e atualmente no meio digital dada a expansão de fluxos de informação, de capital e de pessoas (CANAGARAJAH, 2013)? Estudar as multimodalidades se configura como uma possibilidade de recuperar o papel do sujeito como agente de sua própria história em meio à crise, sobretudo nas fronteiras dos pensamentos, que já são multimodais. Desejável é transculturar as teorias (o que explica parcialmente o título deste artigo), isto é, reconhecer que a ressignificação e produção de conceitos e ideologias passam pela criatividade e recursos multimodais dos que falam e agem da suposta periferia, conforme ilustrarei por um trabalho de estudantes de Letras, mais adiante.

Assinalamos que as relações são relações de poder instável (FOUCAULT, 1997), o que nos impulsiona a pensar que transculturar implica compreender como os mecanismos de dominação acontecem para determinadas pessoas e que problemas surgem em situações específicas a partir da experiência vivida, ao invés de buscar modelos de resoluções sem proceder às adaptações e redesenhos em concordância com as necessidades e interesses locais. Postulamos que a transculturação é parte do pensamento de fronteira porque vai além das dicotomias e permite reflexões complexas por estar baseada no princípio de processos plurilógicos, contribuindo para um planeta em que as semelhanças acontecem em meio às diferenças e não partindo de semelhanças e diferenças. Partir de semelhanças e diferenças remeteria a um prisma típico dos discursos imperialistas e coloniais.

$\mathrm{Se}$, no mundo moderno, as línguas/linguagens aderiram aos territórios e às nações caracterizados por suas ligações naturais entre tais línguas/linguagens, agora não mais. Um dos aspectos desse guarda chuva é a multimodalidade, tratada a seguir.

\section{SOBRE MULTIMODALIDADES E LETRAMENTOS}

A língua/linguagem/languaging é controlada por regras e a estrutura gramatical, a coerência discursiva e a lógica argumentativa devem ser respeitadas. Tudo isso é correto. Mas não é nem a única maneira nem a melhor de produzir, transplantar e transformar conhecimento (MIGNOLO, 2008, p. 222).

Pode-se apreender que nessa citação outras modalidades/modos que não a escrita em si subjazem à comunicação humana, como imagens, gestos, expressões faciais e corporais, fotografias, desenhos, cores, texturas, aromas, sabores, holografia, música, sons da natureza e os produzidos artificialmente como as trilhas sonoras de filmes, enfim, tudo que ocupa espaço físico e/ou virtual ou que é invisível, porém 
sentido sinestesicamente. Ou seja, é algo que a experiência ocidental e grafocêntrica quase nada ou pouco conhece.

Parafraseando Kress (2003, p 35-36), a fala e a escrita são tratadas semioticamente numa paisagem que compreende vários modos disponíveis para representação. Essa paisagem tem adquirido status diferenciado na sociedade das novas mídias, as quais trazem os modos elencados pelo autor.

Com efeito, o conceito de letramento muda com essa perspectiva semiótica, pois a noção de sentido/significado altera. O sentido está correlacionado ao trabalho da interpretação, articulação, aprendizagem, criatividade e transformação, ainda segundo o referido autor. Isso porque, nessa teoria, os recursos são amplos e quando disponíveis aos produtores de sentido permitem que os mesmos, dependendo de suas habilidades, façam remodelagens e recriações de ideias e dos próprios recursos com os quais estão lidando. O objetivo é vivenciar o uso de línguas com oportunidades significativas e gêneros discursivos híbridos e relevantes ao contexto em que estão imersos.

Nesse segmento, é possível relembrar que o corpo é menos importante que a alma (MIGNOLO, 2008), reverberando o fato de que a máquina pode ser considerada a extensão, por exemplo, do braço humano (SANTAELLA, 1997), dado relevante quando se muda o foco para a produção de processos sinestésicos que têm uma analogia com a semiótica. Os movimentos corpóreos, por exemplo, respondem, em parte, pela expansão do conceito de transformação. Seria mais do que mera mudança de desenvolvimento de habilidades, pois a articulação entre formas e estruturas (informação e dados) dentro de um modo (KRESS, 2003, p. 36) não separa sentido de forma. A orientação é a busca por meios de compreender e descrever a integração de tais sentidos em modos específicos como resultado do interesse de quem os constrói.

A experiência do leitor/espectador reforça seu papel ativo ao produzir outro signo que foi recepcionado na forma de texto em que os elementos específicos de um determinado modo estavam presentes e prontos para serem interpretados. A interpretação pode ser uma aproximação dos sentidos (quando o leitor/espectador concordar, corroborar) do produtor de sentidos, mas de qualquer forma, será sempre uma transformação em meio ao conjunto de conhecimento e experiência vivida que o leitor/espectador já possui, segundo Kress (2003, p. 39). Ao fazer isso, ou seja, produzir sentidos modificados, o leitor, segundo esse autor, sabe ou deveria saber que ele dispendeu energia nesse processo. Energia equivale a um trabalho realizado, no sentido da Física (fez esforços mental, físico) e no sentido semiótico, pois a iniciativa muda quem trabalhou ao mesmo tempo em que altera 
o "objeto" que foi trabalhado/interpretado (o texto e seus recursos com os quais foram gerados). Pode-se inferir, assim, que o trabalho interpretativo dos modos é uma forma de aprendizagem e aprendizagem é "dar sentido à subjetividade do produtor de sentido" (KRESS, 2003, p. 40).

Não é desejável que a noção de multimodalidade seja apenas interpretada e repetida. Seu desdobramento e transformação passam por processos transculturais e simultâneos que podem se abrir para epistemologias-ontologias-metodologias fronteiriças. Modos de pensar e agir do colonizado (com posições marcadas por preconceitos e binarismos essencialistas) nos inibe de perceber que as teorias racionais não esgotam os sentidos inundados pela subjetividade de quem narra metaforicamente suas histórias construídas de imaginações e experiências. São discursos e produções outras (obras de arte dos povos que não conheciam e não conhecem a escrita alfabética) que contam com o trabalho amplo da língua/ linguagem. Esse trabalho é necessário para a interpretação. E a interpretação é transpassada por polifonias, transculturalidades alheias e produzida por interesses e desejos no devir atual das histórias e das reconstruções identitárias e multimodais.

Em face aos dados apresentados, a relação língua/linguagem, educação e crítica (FREIRE, 2005) vêm à tona. Uma diferença crucial é desenvolver a capacidade de pensar com as pessoas de acordo com Mignolo, citando Freire (2008, p. 265), e não pensar sobre ou para elas. Analogamente, pensar com a escola, com os estudantes ao invés de pensar sobre ou para eles muda os conceitos de descolonização linguística, educacional e crítica. Em outras palavras, é reinscrever práticas sociais em constante luta, mas não como o alcance do horizonte último de uma epistemologia-ontologiametodologia única, ahistórica e acrítica.

Assim sendo, o pensamento de fronteira contribuiria para "relocar o problema inscrito na diferença colonial (o problema local) antes do método" (MIGNOLO, 2000, p. 306). O pós-ocidentalismo focaliza o problema ao invés de partir do método. Ele assume a diferença colonial com uma genealogia conceitual que emerge da percepção de conhecimentos e línguas/linguagem relegadas às margens transformando as relações de subalternidade.

A multimodalidade, por sua vez, pode ser mais bem caracterizada como sendo espaço transfronteiriço e propício à revisão de questões diretamente ligadas à epistemologia-ontologia- metodologia. Seria uma opção descolonial pelo gesto político apontando para cidadania transfronteira que irradia para outros espaços.

Em resposta às condições da vida diária criadas por processos de globalização e pelas novas interfaces com a diferença colonial, o espírito fronteiriço pode ampliar as noções e práticas de multimodalidade via língua inglesa ou línguas. Ele 
poderá fazer emergir pesos culturais e políticos que estão questionando, resistindo e transformando princípios por meio do enfraquecimento de paradigmas e ethos ocidentais. A autocrítica das margens pelas margens não poderá faltar na teorização que se esboça pelas crises, isto é, pela não celebração de vitórias das margens, mas por networking e interações em que "as pessoas e as comunidades têm o direito de serem diferentes precisamente porque nós somos todos iguais (MIGNOLO, 2000 p. 311$)^{\prime \prime}$.

\section{POR QUE QUE PAÍS É ESSE? E ANOTHER BRICK IN THE WALL SÃO RECUPERADOS POR JOVENS APÓS DÉCADAS?}

Sem respostas fechadas, essa pergunta crucial remete aos loci dos estudantes de Letras de uma universidade pública brasileira num trabalho de conclusão de semestre na disciplina, Língua inglesa VIII, ou seja, com alunos do oitavo semestre de Letras. Atuando como intérpretes, eles criam um vídeo clip a partir de certo inconformismo social, político, econômico e cultural na atmosfera brasileira da ocasião dos tempos atuais ${ }^{7}$. Destarte, a universidade representa um local propício para manifestarem suas potencialidades multimodais (KRESS, 2003) e críticas que presidem desdobramentos históricos de crises educacionais e que estão refletindo na formação de tais estudantes.

A produção de vídeo clip é encenada do lócus do lado de cá do Atlântico e debaixo do norte americano e, portanto, do sul (SANTOS, 2008). Ou seja, da posição de cidadãos que depositaram a confiança em certos políticos ou em profissionais próximos a esses. Os estudantes de Letras sugerem que a ironia é um

\footnotetext{
${ }^{6}$ Música composta por Renato Russo em 1978, época a em que fazia parte da banda Aborto elétrico. Segundo Pantaleão (docente da UFES), durante a ditatura militar, a letra traz a crítica ao cenário político-social da época e se mantem atualizada. Bem próxima aos interlocutores, brasileiros, indaga, questiona sobre o estado da questão do desrespeito a Constituição (desde comunidades até o Senado), da violência generalizada nas regiões brasileiras, crítica ao lixo em sua forma metafórica e plural, ironia aos papéis (documentos que protegem os poderosos e papéis que cada um de nós exerce na sociedade) manchados de sangue. Sutilmente, resvala para uma ambiguidade: "Terceiro mundo, se foi Piada no exterior". Reforça a temática da esperança: "Mas todos acreditam no futuro da nação", "Mas o Brasil vai ficar rico", "Vamos faturar um milhão", mas deixa o refrão Que país é esse? ganhar mais força no final da letra como convite à mobilização dos brasileiros numa guerra que só parece ter começado e o meio de se fazer esse convite é pelo som alucinante típico de rock' nroll. Mais informações em: http://outros300.blogspot.com.br/2013/06/analise-da-cancao-quepais-e-este.html

${ }^{7}$ Em aulas anteriores dessa disciplina, devido a grande repercussão da corrupção no Brasil, essa questão foi amplamente discutida pela sala, o que deve ter inspirado os alunos desse grupo a produzir esse vídeo clip.
} 
recurso poderoso para entender a perplexidade da situação em que alguns políticos e profissionais do entorno (supostamente corruptos) estão na pauta das discussões no país todo.

A multimodalidade que transpassa o discurso é desenvolvida a partir do lugar configurado na fronteira do Estado de Mato Grosso do Sul com Paraguai e Bolívia, com influências de nordestinos, indígenas e ancestralidades locais, gaúchos, dentre outros. É válido lembrar que esse lugar sofre questões políticas da década de 1970, período em que o Estado de Mato Grosso se divide dando origem ao Mato Grosso do Sul, em plena Ditadura militar no país. A divisão tem custo epistemológico por MS ser periferia do Brasil em relação a Mato Grosso, estado considerado mais rico em muitos aspectos. Ancorado na América Latina, o Brasil fica à margem da Europa e dos Estados Unidos e da América hispânica ${ }^{8}$. A presença dos estudantes também é marcada por produzirem sentidos e saberes de dentro de uma universidade no Centro-Oeste brasileiro, num campus universitário situado fora da capital de MS. Portanto, os loci de enunciação (BHABHA, 1994) de tais alunos parecem apartados dos grandes centros culturais e econômicos.

Outra questão que revigora o discurso desses estudantes de Letras são os fatores migratórios e os processos de globalização, os quais não são necessariamente recentes. Entretanto, da forma com que eles vêm configurando o mapa linguísticocultural transformaram a noção de língua/linguagem. Esta era tida como homogênea em discursos que acentuam a relação entre língua/linguagem e questões de identidade, raça, etnia, cultura, poder, memória e performatividade (PENNYCOOK, 2010).

Explorar o potencial epistemológico-ontológico-metodológico nesse lócus de enunciação (BHABHA, 1994) é assumir que a complexidade híbrida daqueles que estiveram ou estão em posição menos favorecida em algum momento da história (nesse caso, os imigrantes fronteiriços e os migrantes, em busca de melhores condições de vida em MS) dá o tom do pensamento de fronteira, cujo princípio é o respeito às diferenças e a protagonização de mudanças sociais que emergem das e nas fronteiras.

\footnotetext{
${ }^{8}$ Segundo Ballestrin (2013), o grupo modernidade/colonialidade começou a ser estruturado em 1998 com Edgardo Lander, Arthuro Escobar, Walter Mignolo, Enrique Dussel, Aníbal Quijano e Fernando Coronil, Javier Sanjinés, Catherine Walsh, Nelson Maldonado-Torres, José David Saldívar, Lewis Gordon, Boaventura de Sousa Santos, Margarita Cervantes de Salazar, Libia Grueso e Marcelo Fernández Osco Santiago Castro-Gómez e Ramón Grosfoguel, Jorge Sanjinés, Ana Margarita Cervantes-Rodríguez, Linda Alcoff, Eduardo Mendieta, Elina Vuola, Marisa Belausteguigoitia e Cristina Rojas. Nesse sentido interpreto que o Brasil não teve participação expressiva e/ou apresenta insuficiente visibilidade internacional no âmbito das teorias e pesquisas relativas à modernidade/ colonialidade.
} 
A produção do vídeo clip se presta a apresentar momentos em que a rotina é uma vez mais reimaginada com recursos e histórias, espaços discursivos de tais estudantes, em que eles apresentam protagonismo, criticidade, criatividade, contestações/questionamentos em associação com a produção e circulação de saberes.

A agência dos estudantes parte de um lugar social específico, isto é, das circunstâncias nas quais enunciam seus discursos multimodais objetivando se apropriarem de um vídeo clip estrangeiro (sua crítica e agência). Seguem produzindo outro vídeo clip local com crítica e agência como reconstrução do projeto global pela perspectiva das margens, com interconectividades ou fronteiras e que, aqui, denominamos transfronteira. Com recursos amadores, eles ampliam os valores apresentados no vídeo clip internacional por meio da ambiguidade de sentidos. Esta, por sua vez, insinua possibilidades interpretativas outras e, portanto, elaboração de alternativas educacionais não pelo descarte e/ou substituição de elementos, mas sim, confrontando-os com epistemologia-ontologia-metodologia criticamente performada ao mesmo tempo em que marca a diferença.

O vídeo em questão revela a inserção das críticas de natureza política ao trabalho multimodal. Nessa esteira, o senso crítico e a localização social de tais autores estão relacionados aos sentidos que se estendem e se mesclam com a língua convencional, seu uso, com as linguagens (visuais, sonoras, gestuais, numa espacialidade específica), com a paisagem montada com elementos que compõem o clima apelando para humor, ironia, criatividade, narrativa corporal e peformatividade (PENNYCOOK, 2010).

\section{TRABALHO COM O VÍDEO}

Uma tela sobe gradativamente mostrando Trabalho em vídeo Língua inglesa VIII, $8^{\circ}$ semestre enquanto os espectadores entram em sintonia com o fundo musical do rock "Que país é esse?" Num primeiro momento, o cantor (Renato Russo) questiona com força como que convocando os brasileiros a refletir sobre seu estado da arte passando para "Que país é esse?" com voz mais cansada denotando esgotamento por conta da situação.

Que aula de inglês é essa nesse país? Que monitoria é essa nesse país? Poderia um interlocutor perguntar ao ver esse início do trabalho em vídeo. Logo em seguida, em caixa alta, lemos: CORRUPTION CLASS. Esse é o título da aula filmada. Os espectadores acompanham o "ponto na lousa!" com a régua que vai 
se alinhando às frases e que é segurada pelas mãos de um professor jovem. Este lê uma frase, pausa e a sala toda repete a mesma frase em seguida. Continua com esse procedimento até a última frase. O "ponto na lousa" é construído com a mescla de imagem gráfica e a atribuição sonora às frases. Conferindo:

\section{CORRUPTION CLASS}

\section{WE TOOK A LITTLE BIT OF THE PUBLIC MONEY BECAUSE WE ARE EDUCATED POLITICIANS AND NOW WE ARE PRISONERS AND; FROM THE BOTTOM OF OUR BROKEN HEART, WE WISH THE BEST EDUCATION FOR ALL BRAZIL.}

Professor: We took a litlle bit

Sala: We took a litlle bit (sala repete em seguida)

Professor: of the public Money

Sala: of the public Money (e assim sucessivamente).

Professor: Did you understand?

Sala: Yeah!

Professor: We are educated politicians.

Sala: We are educated politicians.

Professor: And we are corrupt.

Sala: And we are corrupt.

Professor: Sure.

Sala: Sure.

A partir da repetição da fala do professor de "We are educated politicians", observa-se que a câmera se movimenta e focaliza o professor de pé e, na diagonal, os estudantes com capuzes feitos de material reciclável que lembram envelopes de papel de cor parda emergem. Os rostos são as imagens dos rostos de personalidades da vida política brasileira. São recortes de jornais e revistas dando a ideia de políticos e pessoas que trabalham próximas aos políticos ${ }^{9}$ referenciados no "ponto na lousa". Aproximadamente dois segundos são fixados em cada político. O olhar de cada personagem se dirige para a câmera como se estivesse interagindo como o público brasileiro. Pode-se interpretar que esse público é composto por ouvintes da música

\footnotetext{
${ }^{9}$ As personalidades políticas no vídeo clip pertencem ao cenário brasileiro da última década.
} 
"Que país é esse?" O olhar de cada político é o olhar que sorri e que cativa esse público. Sentados às carteiras da sala de aula, o conjunto de expressão facial em todos eles sugere que estão gostando da aula, participando ativamente e repetindo os comandos do professor. Inseridos nesse pacote de comandos estão as ideologias e os valores da escolaridade.

A multimodalidade (KRESS, 2010, 2003) engendra uma ironia ácida, pois são políticos educados. Educados no sentido de que frequentaram o banco escolar. A formação revela um tipo de educação que os "preparou/formatou" para trair seu povo na forma de suposta corrupção. São educados porque aprenderam que a aparência faz parte da etiqueta social com extensão às escolhas que fazem: eles vestem jeans e camisas de mangas compridas com cores lisas e gravatas. A única mulher usa blusa verde estampada e terninho azul marinho. Imitam os gestos dos políticos: a mulher e um deles apoiam um de seus braços sobre o outro braço na escrivaninha, dois estendem os braços soltos sobre as pernas e outro cruza as mãos sobre as carteiras. Ou seja, estão cientes de que essas posturas são desejáveis.

Os significados irônicos são acionados de começo a fim no "ponto da lousa": as referências ao pouco dinheiro que pegaram do povo, a afirmação de que são políticos educados e que desejam a melhor educação para todo o Brasil do fundo do coração, embora machucado, levam os espectadores ao estranhamento da situação. Porém, ao darem conta da modalização da linguagem e do uso da multimodalidade por meio das cabeças das personagens e não meras máscaras, os espectadores ativam as histórias, narrativas e condições em que tais personagens se encontram. As cabeças físicas não importam mais porque são os protagonistas e seus supostos atos de corrupção que estão chamando a atenção nesse momento, uma estratégia criativa que se realiza pelas escolhas multimodais do grupo em questão.

Abruptamente, o espectador é tomado e levado de um contexto para outro com o som de Another brick in the wall ${ }^{10}$ e com a cena do professor de idade avançada, se comparada a do professor brasileiro e jovem no primeiro momento. $\mathrm{O}$ olhar de quem assiste foca rapidamente nos sapatos pretos que se movimentam e caminham em direção única (sugerindo o princípio da linearidade epistemológica-ontológicametodológica) à escada.

\footnotetext{
${ }^{10}$ Música composta por Roger Waters e gravada pelo grupo Pink Floyd em 1979. A composição da letra e o vídeo clip fazem alusão aos orfanatos e às escolas em que o conceito de educação se igualava a controle de pensamento (thought control), repressão aos alunos ao invés de inspiração. Apresenta ironia com o uso de duas partículas negativas em We don't need no education acentuando o uso mais coloquial da língua inglesa. Muitos críticos repudiaram o tipo de educação oferecido por essas escolas no Reino Unido na época. Nesse prisma, os estudantes eram preparados para serem meros consumidores de conhecimento.
} 
Os jovens estudantes vestem uniformes formais, ou seja, ternos para os alunos e saia e camisa para as alunas. A subida aos degraus de meninas e meninos vem acompanhada das batidas de We don't need no education. Enfileirados, eles prosseguem andando para adentrarem a um corredor e saírem sentados às carteiras enfileiradas, desta vez, com máscaras iguais remetendo a um dos aspectos da globalização em que as diferenças individuais são processadas ao passarem por um portal (Internet) para saírem homogêneas, como mostra a seguinte figura:

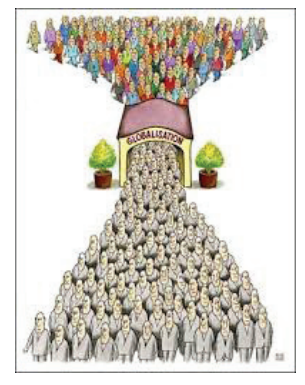

Imagem hospedada em:

http://pamamapa2397.blogspot.com.br/2011/10/globalizacao.html

Formam-se duas fileiras e, entre elas, a figura do professor de pé com a bengala (instrumento que usa para bater nos alunos) no plano de fundo. Sapatos se movimentando, o professor gritando, corpos andando enfileirados em ternos e máscaras, duas filas longas mostrando tais corpos, sapatos e tornozelos cobertos de meias vão dando a ideia de que a exaustão tomará conta da cena que se prenuncia.

Todavia, antes do espectador pensar a esse respeito, eis que chega novamente a figura do professor severo no plano de fundo. Ao seu lado esquerdo, no plano frontal, a sombra do professor brasileiro e jovem aparece ganhando contornos vivos, puxando os supostos corruptos pelos braços, um a um em direção às grades da delegacia. Esse professor, que agora é um agente de segurança, veste camiseta preta com colarinho azul royal e usa um cassetete na mão esquerda ${ }^{11}$.

Os políticos, prisoners, caminham e marcham enfileirados e estendem o braço direito no ombro do colega da frente. A música de fundo é Another brick in the wall.

\footnotetext{
${ }^{11}$ Esse momento beira um remix/mashup que hibridiza o vídeo da autoria dos estudantes com uma cena do vídeo clip Another brick in the wall muito por conta dos dois professores estarem na mesma tela. $\mathrm{Na}$ música, remix é uma versão diferente de uma canção popular originalmente gravada. É a mescla de um trecho de uma dada melodia numa outra resultando numa produção que entrelaça duas ou mais fontes, o que pode ser feito pelo próprio músico ou por outro. No caso deste artigo, remix significa que houve a recriação dos discursos e multimodalidades suscitando sentidos trans-fronteiriços e irônicos.
} 
O policial encaminha um a um por trás das grades (portão com grades altas num corredor de salas de aula na universidade). Eles seguram as grades com as duas mãos e vão se posicionando lado a lado de frente para o público. Continuam marchando, agitando as cabeças e acompanhando o ritmo da música que, a essas alturas, é apenas instrumental. A câmera focaliza rosto por rosto da esquerda para a direita e em seguida o caminho inverso.

A montagem da cena e a performatividade (PENNYCOOK, 2010) dos atores parecem caracterizar que estão plenamente satisfeitos e felizes com esse tipo de escolaridade, conforme seus rostos e olhares que sorriem ou que expressam simpatia. E não precisando ser "verdadeiros", os sorrisos e simpatias dão efeito de alegrias. Dito de outra forma, não importa tanto a veracidade dos fatos e sim seus efeitos que dali emanam.

No vídeo clip em curso, os ouvidos voltam a se sintonizar com a trilha sonora de We don't need education. Entram em cena os alunos derrubando um muro da escola conservadora como um gesto de emancipação, ruptura dos moldes tradicionais de opressão e dominação com paradigmas educacionais centrados em regimes de verdades verticalizados e, portanto, unilaterais.

A parte que diz respeito à prisão dos corruptos beira um final que é condizente com a noção de esperança/possibilidade presente na letra de "Que país é esse?" Aparentemente, há uma vontade desses autores/produtores do vídeo clip (alunos de Letras) de querer entender as situações que compõem o amplo cenário político e econômico do país. Aglutinam uma tensão em que os supostos corruptos encenam o ponto que lhes é comum, o crime, preservando suas histórias peculiares. Isso parece ser o ponto chave da criatividade que se move pelas possibilidades e não a inércia; fazer o impossível, pelo possível.

Nessa produção, a visão da escola não é um império em si, e sim uma pluralidade de relações, sendo algumas mais visíveis que outras. A escola não forma apenas supostos corruptos, mas responde também por profissionais que participam do desfecho do vídeo clip em questão, ou seja, os policiais, investigadores, advogados, juízes seguranças das cadeias, entre os demais e todos cerceados por dispositivos de controle e seleções constantes. A perspectiva crítica é a que interroga constantemente sobre o trabalho complexo da escola, do professor etc. e que não desiste de lutar com a escola e não com a sua eliminação. Se os estudantes aprendem com a escolaridade ou apesar dela, então eles não são completamente submissos a ela, usam princípios e estratégias aprendidas na escola para construir contrapontos e agência a favor deles (FREIRE, 2005) deslizando entre o conservadorismo e a criatividade, fazendo emergir novas ambiguidades e complexidades, como esse vídeo clip intenta ilustrar. 
A crise educacional que o trabalho de produção multimodal apresenta não é "resolvida" pelos mesmos moldes em que ela se criou e se estendeu. Se no vídeo clip estrangeiro, os estudantes fogem da escola repressora, no vídeo nacional o professor permanece na escola em que foi cúmplice da formação da classe. Ele reaparece como sendo o segurança que conduz os políticos à cadeia, simbolizando que a escola vive em constantes dilemas e tensões que necessitam engendrar autocríticas abertas nas reflexões para lidar com os próprios paradoxos e os que emergem na sua relação com outros conflitos religados ao mundo social.

Nessa montagem irônica, em ambos os casos, há um modelo de professor baseado na lógica única, ou seja, a da autoridade. A autoridade impõe ordem, homogeneidade, disciplina, repetição, legitimação de padrões e de normatividade. Ficam de fora dessa seara, a intersubjetividade, o pensamento paralelo, a percepção pluralizada, a intertextualidade com o mundo, a negociação que transpassa outros sentidos e conhecimentos, portanto a possibilidade de ampliações de agência no tecido social com a promoção de conceitos mais complexos no que concerne à epistemologia-ontologia-metodologia. Consequentemente, a participação destes na sociedade de aprendizagens para práticas ampliadas de cidadania parece redutora.

No que se refere ao papel do professor, é pertinente dizer que o professor brasileiro e jovem é tranquilo, seguro. Ele constrói uma estratégia didática que aparentemente inclui os estudantes ativando as suas vozes. Mas antes de dar oportunidade, dita o modelo a ser seguido, o padrão de pronúncia e de entonação das frases que compõem o discurso/ponto na lousa. As intersubjetividades se escondem embaladas no coro de vozes uniformizadas. Espera-se, nesse modelo de aula, a reprodução dos valores de uma época de repressão fazendo alusão à manutenção do capital simbólico (BOURDIEU; PASSERON, 1982) do professor e à subserviência aos sistemas políticos do país figurado num poder grassado nas mãos de supostos corruptos.

Já no modelo do professor mais velho, o poder é erigido pelo professor que bate no aluno e grita com a classe. Esse poder é duplo, pois ele representa a instituição para a qual trabalha e honrá-la ("vestir a camisa", promove e mantem o controle de qualidade total à moda neoliberal) é parte de seu trabalho.

$\mathrm{Na}$ crítica que o vídeo americano sela, a escola tradicional é descartada porque sua função não é senão a de vencer os paradoxos, as homogeneidades, contingências ${ }^{12}$, incertezas e ambiguidades pelo uso do poder rígido da figura

\footnotetext{
${ }_{12} \mathrm{Na}$ ideia de contingência (diferente da de conteúdo, que pressupõe um criador) as ordens se fazem em contextos. Aqui, o processo é salientado e não os pontos de partida e de chegada homogeneamente concebidos.
} 
do professor como se todas as contradições fossem necessariamente superáveis. O resultado revelado é previsível: formação de estudantes rebeldes com a fuga triunfalista desorquestrando a ordem e progresso da escola. Não há exceção nessa visão essencialista. Ela é radicalmente construída por lentes dicotômicas proclamando a verdade determinista, única e universal, criticadas por Bhabha (1994), Canagarajah (2013), Derrida (1997), Freire (2005), Mignolo (2000, 2008, 2010), Nolasco (2013), Pennycook (2010), Quijano (2005), Souza (2004), cada qual com suas diferenças contextuais.

A perspectiva na performatividade americana enaltece a raça pura, do branco europeu, consolidada por narrativas preponderantes e unívocas e pelas grandes narrativas das histórias ocidentais e projetos modernistas encrustados em experiências logocêntricas que separaram o mundo entre cristão e não cristão; civilizados e primitivos; teoria e prática; epistemologia, ontologia e metodologia etc., já aqui explanados.

Os estímulos são vários. Pontuando: a) a própria agressão e rebeldia, como simbologia do colonialismo de poder sendo exercido, deflagradas na escola conservadora; b) a totalidade e radicalismo de We don't need no education $;$ c) as imagens sobre violência mostradas e d) o desfecho trágico que dilui as diferenças identitárias e os lugares discursivos dos estudantes. A educação na modernidade eurocêntrica se via obrigada a educar, civilizar, emancipar as pessoas removendo todos os obstáculos (diferença) e, para tanto, o recurso da violência se fazia necessário. Vitimados e colonizados, os estudantes que se formam nesse sistema radical podem ser mais violentos que seus próprios colonizadores.

As identidades do professor e dos alunos são mostradas como sendo categorias pré-estabelecidas e embasadas, portanto, numa visão de ética que restringe o espectro interpretativo. $\mathrm{O}$ risco da generalização condiciona comportamentos interpretativos que facilmente levam à reflexão e à agência estereotipadas na sociedade. Ou seja, apenas criticar e abandonar a escola tradicional poderá gerar outra pirâmide de valores (atribuindo mais poder a quem está no seu topo) e enveredar para a intolerância das diferenças. A saída que o produtor encontra é o despejo dos alunos às ruas da vida, dando a entender que todos os alunos, pais e autoridades escolares pensam da mesma forma.

Sem uma sinalização de orientação educativa o vídeo clip reproduz a visão romântica de que a liberdade/emancipação existe plena e homogeneamente para todos ali. Deixar uma escola conservadora poderá não adiantar se adentrar outra com os mesmos moldes políticos educacionais ou substituir uma pela outra simplesmente acreditando na visão romântica de que as outras escolas estão imunes 
de qualquer problemática, sejam elas do setor público ou privado. Enfim, não há uma concepção de língua/linguagem, sujeito, conhecimento, cultura, identidade, poder, linguagem que articule as diferenças raciais, étnicas, de classe social, de gênero entre as demais considerando as convergências e divergências epistemológicasontológicas-metodológicas.

Não é demais lembrar que, no projeto fronteiriço, há várias formas de dominação e ela nunca deixará de existir. Ele não dispensa a participação do lado hegemônico na empreitada de possíveis transformações. Grupos de poder podem se interessar por outros engajamentos que melhorem a condição de seus subordinados ao mesmo tempo em que aqueles prolongam seu tempo no poder.

Outra preocupação constante é externar a alternativa de pensamento ao invés de apagá-la deixando um espaço lacunar em que a ambiguidade de sentidos e saberes possa ser reinventada nas mentes dos espectadores. Estes se incumbem de interpretar e criar outros sentidos que, como na produção do trabalho final, não estão circunscritos ao contexto imediato, mas se expandem para sentidos religados ao contexto sociohistórico maior no qual e do qual fazem parte.

Acentua-se assim, a natureza polifônica do trabalho da língua/linguagem (BAKHTIN, 1999) que permite a entrada de vozes que questionem que interesses são focalizados e que outros são deixados de lado quando se aborda/trata de escolhas ambíguas nas traduções transculturais (DERRIDA, 1994) com base em lócus transfronteiriço dialogando com as vozes do sul (SANTOS, 2008), em consonância com o que foi aqui já postulado. Essas traduções demandam um tipo diferenciado de engajamento dos estudantes, isto é, um diálogo crítico e uma performatividade que suspende (não elimina) as ideologias da fonte de onde se bebe (Another brick in the wall) para promover outros significados e saberes "fluidos", mas ancorados num determinado contexto de agência (Que país é esse?). Eles sugerem outras visões nos espectadores sem impor uma única.

O vídeo clip dos estudantes de Letras produz uma alternativa à linearidade como uma totalidade presente em Another brick in the wall (que traz um epistemicídio travestido de ordem e progresso) e metaforiza o hibridismo na origem. A produção crítica na perspectiva de repertórios (éticos, criativos e críticos) que transpassam a multimodalidade transfronteira é gerada pela releitura de um produto global da visão local que não se rende ao abismo discursivo atravessado por condições monoculturais. Ou seja, nesse momento, pela inserção de autoria como produto nacional e pela mescla da cena em que ambos os professores estão presentes sugerem a ideia de mashup/remix não apenas tecnicamente concebido, mas principalmente a 
de mashup/remix que aposta em rupturas das epistemologias-ontologias-metodologias universalizantes.

Duas epistemologias-ontologias-metodologias se encontram: de um lado, a exposição de uma aula tradicional com o uso de lousa e imitação do modelo do professor e, do outro, uma aula (trabalho de avaliação na disciplina em questão) com o uso da nova mídia e ambiguidade suscitando reflexões no espectador. São dois mundos que coexistem com uma distância que se permite ser porosa, de tempo em tempo, deixando traços de contato transcultural conflituoso.

Ampliando e transformando esse paradigma, um novo local ao mesmo tempo físico e imaginário e de coexistência com a diferença é articulado com outra lógica. A ambiguidade, leveza multimodal, ironia, o humor e o caráter não prescritivo da escolarização como contingência aos espectadores compõem uma ilustração de um projeto multimodal transfronteiriço e coletivo. Modesto do ponto de vista de recursos físicos, mas com complexidade e ambiguidade de conhecimento construído no/ pelo lócus transfronteiriço e atuação performativa. O espaço se abre para que outras "verdades" possam proliferar com posições discursivas assentadas em paradoxos. $\mathrm{Na}$ parte que diz respeito à produção dos estudantes de Letras, a identidade é relacional, aberta e se reconstitui pelas diferenças e paradoxos. Ao mesmo tempo em que a escola produz cidadãos $X$ (exemplo: os supostos corruptos), ela pode produzir cidadãos $Y$ (exemplo: a figura da autoridade que prende os corruptos). Evidentemente, se a metodologia for apenas a da repetição do modelo do professor, a probabilidade dos cidadãos assim formados de serem unívocos tende a aumentar. De qualquer forma, vale ressaltar que a escola, como instituição de ensino opera em prol da formação de cidadão que, em princípio, deveria ser de bom caráter. Não obstante, ela não pode garantir resultados como muitos creem.

O desfecho do trabalho dos estudantes demanda reflexões, pois a ideia de poder (FOUCAULT, 1997) é uma vez mais estranhada com vistas a realçar o movimento do espaço em que as diferenças e ambiguidades, na relação com o outro, circulam permanentemente. Não existe uma separação rigorosa entre o eu e o outro e seu entorno; a diferença serve para provocar mudanças nas teorias, nos conhecimentos. Se o lócus de enunciação muda, os sentidos e saberes podem ser resituados. O vídeo clip Another brick in the wall saiu de uma localização particular e se tornou global pelos recursos tecnológicos e pelas viagens da banda naquele momento histórico de sucesso. O grupo de estudantes se apropriou dessa construção ideológica e provocou uma intervenção, cujos sentidos e saberes se deslocaram para a produção de outra visão de escola, abrindo mão de suas "verdades" historicamente introjetadas em suas formações escolares. Eles não substituem o modelo do professor 
autoritário por outros modelos, o que seria uma vontade modernista. Por meio de ironias multimodais dão sinais de que o radicalismo não funciona por muito tempo.

Dado o exposto, o acesso às novas mídias propicia a abertura para autorias dos estudantes de Letras na base do que eles/elas conhecem, trazem de experiência vivida de seus loci de enunciação (BHABHA, 1994) com práticas multimodais que vão modificando suas maneiras de perceber e agir no mundo e não acesso aos recursos tecnológicos para reproduzirem e reforçarem pressupostos e valores que têm encontro marcado com propostas neoliberais, competitividade no mercado de trabalho, hierarquização de conhecimentos e saberes, mas sim, a expansão de visões e práticas sociais mais condizentes com os contextos de interesses e necessidades de tais estudantes.

A redistribuição de poder pode começar na sala de aula e contagiar outras coletividades na base de conhecimento e agência que emana de um grupo de estudantes que resiste em fazer a simples transposição de uma perspectiva linear e de maior status simbólico (no caso do clip original) ao contexto de realização de uma atividade para obtenção de notas para a avaliação na disciplina de língua inglesa. Isso desmistifica o fato de que os estudantes estão interessados em apenas obter notas suficientes para aprovação nas disciplinas. Aparentemente, aqui, eles aprendem a desaprender (SANTOS, MENESES, 2010) e se engajam na criação de um vídeo clip pensando e se posicionando não em isolamento, mas tecendo relações com outras zonas de contato, ou seja, com o mundo político e social brasileiro da época. Essas redes transculturais costumam propiciar mudanças da posição de meros debatedores para autores de ações, como esse vídeo clip, em que rompem com meras sequências epistemológicas-ontológicas-metodológicas. Ainda, convém lembrar que não se submeter às imposições curriculares hegemônicas com suas consequências sociais, educacionais, políticas e econômicas pode representar uma oportunidade para os estudantes reverem seus princípios, considerando que a grande maioria deles/delas advém de contextos em que a escolaridade acentuou prismas de cunho neoliberal para manter o status quo das instituições e grupo mantenedores de poder.

\section{CONSIDERAÇÕES FINAIS}

Forçar a entrada de culturas, ideologias e valores centrados em paradigmas dos centros colonizadores por meio de mercado e da mídia, acarretando perdas socioculturais, históricas etc. do lado mais fraco acaba por influenciar projetos 
esvaziados das necessidades culturais, sociais, étnicas, raciais, políticas e educacionais.

Em decorrência disso, muitas histórias (das periferias nem sempre periféricas na acepção ampla da palavra) estão ainda sendo esperadas para ser compartilhadas. Os colonizadores que não inventaram a América Latina podem aprender com essas histórias. Dito de outra forma, com maneiras que incluem o ouvido, o visto, o olhado, o falado, o cantado, o desenhado, o filmado, o performado, o interpretado, o ressignificado. As tecnologias podem ajudar nesse sentido. Essas histórias não são menos, se ouvidas e entendidas como valores que confrontam, resistem, subvertem e modificam os poderes centralizados (FREIRE, 2005). Estudantes de escolas públicas podem atravessar fronteiras que não puderam, historicamente falando. Da periferia, os discursos críticos propiciam a ressignificação das teorias que migram para elas de modo que aquelas sejam assumidas como abertas e móveis.

Outro ponto a ser retomado, aqui, tem a ver com o esforço para a compreensão de como a colonialidade do saber (QUIJANO, 2005) opera considerando detalhes históricos multidimensionais. As diferenças coloniais e a colonialidade de poder permeiam o trabalho da língua/linguagem e se a escolaridade tradicional fundamentada em currículos de conteúdos estáticos, conforme dito na introdução deste artigo, também é merecedora de descolonização e de transculturação. Então "é preciso reconceituar linguagem transnacional e transimperial, letramentos, e literaturas" (MIGNOLO, 2008, p. 220).

Dessa forma, o pensamento de fronteira (MIGNOLO, 2000) admite várias formas em diferentes locais, mas com pressuposto de que se renovem não como marginais/ periféricos e sim como potencial para que as histórias locais e projetos globais produzam sentidos e saberes graças às diferenças coloniais. Ele é compreendido como relocação do pensamento e consciência da geopolítica de onde se constrói e de onde se interpreta/valida/transforma/expande o conhecimento, pode representar uma saída para ressignificar línguas/linguagens de forma responsável e ética, assumindo a transculturação (tradução transcultural) e invocando o lócus de enunciação (BHABHA, 1994) dos agentes que atuam em espaços de produção de conhecimentos e, portanto, de pesquisas.

Percebe-se que as fronteiras se complexificam com as mídias digitais dando continuidade para a possibilidade de novos loci de enunciação com aqueles que vivem e refletem a partir de revisões de sentido e saberes. Descolonizar as multimodalidades do centro que reproduzem suas epistemes mundo afora para dar espaços de traduções de significados contextuais (SOUZA, 2004) possibilita a expansão de práticas cidadãs importantes no mundo presente. Essa atitude não 
mantem os princípios hegemônicos incólumes. Ao invés disso, partirá de loci em espaços nas "ex-colônias" sem serem pontos de chegada, e sim, processos contínuos de reemergência de performatividade (PENNYCOOK, 2010), sentidos, saberes.

Destarte, clamar por descolonização de sentidos e de saberes não significa que haja um modelo de epistemologia-ontologia-metodologia pronto ou préestabelecido e rígido. O limite pode ser um céu que propulsione alternativas criativas e multimodais em que a escola é objeto e sujeito a um só tempo. Isso significa elaborar e executar projetos sem deixar que uma performatividade global passe a ser de todos os locais ou sem permitir que uma epistemologia-ontologiametodologia local passe a ser a única global possível. A retroalimentação pode ser mais produtiva.

Ao proceder à leitura das multimodalidades, muitas interpretações que considerem os diversos loci de enunciação podem fazer as discussões avançar, isto é, pensar como o incômodo dos estudantes (a crítica à corrupção e à educação) se alojou em forma de ambiguidade, engrossando o coro daqueles que são peritos em criar o inesperado, o divertido e que atravessam fronteiras ao mesmo tempo em que são influenciados por essas mesmas fronteiras. No caso dessa produção em vídeo clip, pode-se dizer que a agência fronteiriça é representada pela ruptura nos moldes tradicionais de trabalhos acadêmicos normalmente restritos à produção escrita e seminários seguidos de avaliação formal. Assim, podemos falar de cultura participativa propiciando mudanças nos conceitos de aprendizagem, no papel do professor e na função social das tecnologias de informação e comunicação e da universidade na sociedade contemporânea de aprendizagens.

A manutenção das ambiguidades, dos matizes, dos hibridismos e do sotaque local são partes de uma prática transfronteira de produção de vídeo. Os estudantes de Letras aproveitaram a própria condição de habitantes de fronteiras (não apenas territorial), prática desejável para uma educação com epistemologia-ontologiametodologia instigante e não prescritiva. $\mathrm{O}$ bom da história e do tempo é que eles não param. Portanto, os critérios que serviram para a subserviência de alguns grupos, não fazem mais sentido, de modo que aqueles que sabiam escrever e que escreveram a história com valores dos "vencedores" grafocêntricos (linearidade na forma de construir conhecimento começando pela Grécia e chegando até a construção de conhecimento no Atlântico Norte) estão tendo trabalho de dar continuidade à suposta hegemonia. Uma mescla de questionamentos, críticas e autocríticas, táticas e estratégias para geração de conhecimentos alternativos é demandada de todos os lados: leveza, filiações, tensões, retomadas, posicionalidade móvel e reaberta para negociações. Consequentemente, um reposicionamento de línguas/linguagens, 
multimodalidades, culturas e pessoas em que as diferenças são concebidas em suas diversas temporalidades e não meros relativismos é sugerido.

\section{REFERÊNCIAS BIBLIOGRÁFICAS}

BAKHTIN, M. (1999). Marxismo e filosofia da linguagem. $9^{\circ}$ ed. São Paulo: Hucitec.

BALLESTRIN, L. (2013). América Latina e o giro decolonial. In: Revista Brasileira de Ciência Política, Brasília, v.11, pp. 89-117.

BHABHA, H. K. (1994). The Location of Culture. London and New York: Routledge.

BOURDIEU, P.; PASSERON, J. C. (1982). A Reprodução. Rio de Janeiro: Livraria Francisco Alves Editora.

CANAGARAJAH, S. (2013). Translingual practice: global Englishes and cosmopolitan relations. London: Routledge.

DERRIDA, J. (1997). Of Grammatology. Baltimore: The Johns Hopkins University Press.

FOUCAULT, M. (1997). Microfísica do poder. Tradução e Organização Roberto Machado. Rio de Janeiro: Graal.

FREIRE, P. (2005). Pedagogia da tolerância. São Paulo: Editora da UNESP.

KRESS, G. (2010). Multimodality. A social semiotic approach to contemporary communication. London and New York: Routledge.

KRESS, G. (2003). Literacy in the new media age. London and New York: Routledge.

MIGNOLO, W. (2000). Local bistories/global designs. Coloniality, subaltern knowledges, and border thinking. Princetown: Princetown University Press.

MIGNOLO, W. (2008). Desobediência epistêmica: a opção descolonial e o significado de identidade em política. Tradução de Ângela Lopes Norte. Disponível em: <http:// www.uff.br/cadernosdeletrasuff/34/artigo18.pdf $>$. Acesso em: 08 de jan. 2015.

MIGNOLO, W. (2010). The geopolitics of knowledge and the colonial difference. Disponível em: $<\quad$ http://waltermignolo.com/the-geopolitics-of-knowledge-and-the-colonialdifference/ $>$. Acesso em: 17 de jun de 2015.

NOLASCO, E. (2013). Perto do coração selbaje da crítica fronteriza. São Carlos: Pedro \& João Editores.

PENNYCOOK, A. (2010). Language as a local practice. London and New York: Routledge.

QUIJANO. A. Colonialidade do poder, eurocentrismo e América Latina. In: LANDER, E. (Org.). (2005). A colonialidade do saber: eurocentrismo e ciências sociais. Perspectivas latinoamericanas. Buenos Aires: Colección Sur Sur, pp.118-142.

SANTAELLA, L. O homem e as máquinas. In: DOMINGUES, D. (Org.). (1997). A arte no século XXI: a humanização das tecnologias. São Paulo: UNESP, pp. 33-44.

SANTOS, B. S.; MENESES, M. P. (Orgs.). (2010). Epistemologias do Sul. São Paulo: Cortez.

SANTOS, B. (ed.). (2008). Another knowledge is possible. Beyond Northern epistemologies. London, New York: Verso. 
SOUZA, L. T. M. De Hibridismo e tradução cultural em Bhabha. In: ADBALA, Jr., B. (2004). Margens da cultura: mestiçagem, hibridismo e outras misturas. São Paulo: Editorial Boitempo, pp.113-134.

Recebido: 29/01/2016

Aceito: 05/07/2016 